\title{
Regional energy demand in Japan: dynamic shift-share analysis
}

\author{
Akihiro Otsuka
}

\begin{abstract}
Background: To investigate the future trends of energy demand in Japan accurately, it is necessary to clarify the factors that determine the fluctuations in energy demands across regions. Specifically, it is necessary to clarify whether the energy demand fluctuations across regions arise from compositional factors, that is, differences in energy users, or from regionally unique factors.

Methods: This study analyzes the determinants of energy demand change to clarify the factors that have affected the fluctuations in regional energy demands in Japan, using dynamic shift-share analysis.

Results: The results show that the energy demand fluctuations can be explained by compositional effects and regional effects. With regard to the compositional effects, the energy demand growth increased most remarkably in the regions that specialize in residential and commercial activities. However, energy demand did not increase in the regions that specialize in manufacturing activities. With respect to the regional effects, there were constraints on energy demand in big-city regions because of the improved energy intensity achieved through energy conservation.

Conclusions: The results imply that having a mixture of industry and civil sector activities in a region potentially flattens out the fluctuations in energy demand changes. This finding suggests that when moderating the change of regional energy demand, it is important to diversify the industrial structure in each region.
\end{abstract}

Keywords: Regional energy demand, Regional energy consumption, Dynamic shift-share analysis, Region, Japan

\section{Background}

The recent ambitions of the Japanese government to improve consumption and conservation include the development of an energy master plan (METI [1]). To create an aspiring political instrument as a master plan, it is essential to thoroughly analyze the present structure of energy demands in Japan. The present study provides this analysis, in terms of the regional and the sectoral aspects relevant to the energy demand in Japan during 19902011. Japan's energy demands grew throughout the 1990s and 2000s. The energy demand in Japan increased at an annual average rate of $0.33 \%$ from 1990 to 2011, which was in line with economic growth $(0.32 \%)$. However, regional differences in the energy demand increases are apparent in that period; e.g., Japan's provincial energy demand increases differed from those in its big-city

Correspondence: otsuka@yokohama-cu.ac.jp

Association of International Arts and Science, Yokohama City University, 22-2 Seto, Kanazawa, Yokohama 236-0027, Japan regions, such as the Tokyo metropolitan area (called the Capital Region in this article), Kansai, and Chubu.

To investigate the future energy demand trends in Japan accurately, it is important to clarify the factors that determine the energy demand fluctuations across Japan's regions. Specifically, it is necessary to clarify whether the energy demand fluctuations across regions are because of compositional factors, that is, differences in energy users, or are because of regionally unique factors. Globally, there is very little previous research on regional energy demands, because of a lack of relevant data. Bernstein et al. [2] and Metcalf [3] targeted individual states in the USA, and Raupach-Sumiya et al. [4], Otsuka et al. [5], and Otsuka and Goto [6] investigated regions in Germany and Japan. However, each of these studies analyzed the factors determining the energy efficiency, rather than the dynamic changes in the regional energy demand. This article clarifies the

\section{Springer Open}


factors that bring about energy demand changes in Japan's regions, by applying a shift-share analysis to newly released regional energy demand data. To the best of the author's knowledge, there are no previous cases of applying shift-share analysis to regional energy demand analysis.

Shift-share analysis, first introduced by Dunn [7] in 1960 , is an analytical method often used in the field of regional science. This method decomposes the relevant factors affecting an economic system, factors that relate mainly to production and employment changes. Shiftshare analysis uses identical equations to analyze the growth rates by industry for each region. It uses three factors: the national effect (factors common among all industries nationally), the compositional effect (industryspecific factors at a national level), and the regional effect (factors unique to each industry at a regional level). The method then evaluates the contributions of each effect to the overall regional growth rate (e.g., Dinc and Haynes [8]; Haynes and Dinc [9]). Shift-share analysis has many proponents; however, it is also criticized for numerous different reasons (Dawson [10]; Knudsen and Barff [11]). There are many extensions and revisions of Dunn's [7] traditional method (Artige and Neuss [12]; Barff and Knight [13]; Esteban-Marquillas, [14]; Haynes and Dinc [9]; Haynes and Machunda [15]; Markusen et al. [16]; Marquez et al. [17]). Notably, Barff and Knight [13] propose a dynamic shift-share analysis that applies the traditional analysis to cross-year data, a method that is adopted in many subsequent studies (e.g., Hirobe [18]; Kobayashi [19]; Mitchell and Carlson [20]; Nissan and Carter [21]; Shi et al. [22]). Barff and Knight's [13] dynamic shift-share analysis solves some of the well-known problems with Dunn's [7] static shift-share analysis.

This study uses the dynamic shift-share analysis method (which is under continuous development) to analyze Japan's regional energy demands. Dynamic shiftshare analysis analyzes the fluctuations in the overall energy demand in regions, according to the compositional effect (arising from the type of energy users) and according to regionally unique factors. This clarifies the dominant factors influencing the total energy demand changes in each region. ${ }^{1}$ Additionally, it is possible to investigate the effects of the efficiency measures through the regional effect.

This article aims to analyze the total energy demand changes by Japanese region. The article analyzes the changes according to the national effect, the compositional effect, and the regional effect, by applying dynamic shift-share analysis to the ratio of total energy demand change. Finally, the article clarifies the factors that cause the fluctuations.

The "Methods" section describes how the dynamic shift-share analysis is applied to analyze the regional energy demand and provides an explanation of the data. The "Results and discussion" section describes the analysis results, while the "Conclusions" section presents the conclusions and suggests some future research directions.

\section{Methods}

\section{Analytical framework}

First, by applying shift-share analysis to total energy demand changes for user $i$ in region $j$, it is possible to divide these changes into three components.

$$
g\left(E_{i j}\right)=g(E)+\left[g\left(E_{i}\right)-g(E)\right]+\left[g\left(E_{i j}\right)-g\left(E_{i}\right)\right],
$$

where $E_{i j}$ is the energy demand for user $i$ in region $j ; E_{i}$ is the energy demand $\left(E_{i}=\sum_{j} E_{i j}\right)$ of user $i$ for the entire nation; $E$ is the energy demand $\left(E=\sum_{i} E_{i}\right)$ for the entire nation. $g(\cdot)$ is a function that expresses the rate of change of each variable. Concretely, the function of energy demand $E$ can be expressed as

$$
g\left(E_{t}\right)=\frac{\Delta E_{t}}{E_{t}}
$$

where $t$ is the time. On the right-hand side of (1), the first item is the national effect $g(E)$, the second item is the compositional effect $\left[g\left(E_{i}\right)-g(E)\right]$, and the third item is the regional effect $\left[g\left(E_{i j}\right)-g\left(E_{i}\right)\right]$. The national effect is the rate of change in the national energy demand. If each region has the same rate of change as the rate of change for the entire nation, then the national effect in each region would be that value. The compositional effect shows the degree by which the national energy demand of user $i$ exceeds the rate of change of the national energy demand. This shows the difference in the specific rate of change for user $i$, and it can be described as a compositional effect that is unique to user $i$. The regional effect shows the degree that region $j$ 's energy demand of user $i$ exceeds the rate of change of the national energy demand of user $i$. Because there is a difference between region $j$ and the entire nation with regard to the same user, this is not a user-specific effect; hence, it expresses a regional-specific effect.

The rate of change of the total energy demand by region can be calculated using the rate of change of the energy demand by user for the region. In other words, the rate of change of the energy demand of region $j$ can be calculated from the rate of change of the energy demand for user $i$ in region $j$ according to

$$
g\left(E_{j}\right) \equiv \sum_{i} s_{i j} \cdot g\left(E_{i j}\right)
$$

where $S_{i j}=E_{i j} / E_{j}$. Note that $E_{j}$ is the energy demand of region $j$. The question arises of whether to make the calculation of $s_{i j}$ the beginning or the end of the observation period. One proposed solution is the dynamic shift- 
share analysis mentioned in the "Background" section. ${ }^{2}$ Instead of conducting shift-share analysis over a long period, the dynamic version conducts shift-share analysis over a short period in each year and aggregates the values for each year (Barff and Knight [13]). This article adopts this calculation method and applies a dynamic shift-share method to the regional energy demand data.

Using (1) and (2), the rate of change in energy demand for region $j$ can be resolved as

$$
\begin{aligned}
g\left(E_{j}\right)= & g(E)+\sum_{i} s_{i j}\left[g\left(E_{i}\right)-g(E)\right] \\
& +\sum_{i} s_{i j}\left[g\left(E_{i j}\right)-g\left(E_{i}\right)\right] .
\end{aligned}
$$

On the right-hand side of (3), the first term is the national effect $g(E)$, the second term is the compositional effect $\sum_{i} s_{i j}\left[g\left(E_{i}\right)-g(E)\right]$, and the third term is the regional effect $\sum_{i} s_{i j}\left[g\left(E_{i j}\right)-g\left(E_{i}\right)\right]$. The national effect is the rate of change in the national energy demand. If each region has the same rate of change as the rate of change for the entire nation, then the national effect in each region would be the rate of change for the entire nation. The compositional effect is the aggregate of the compositional ratio for each user of region $j$ multiplied by the factors specific to user $i$, and its value depends on the compositional ratio of the users of each region. The regional effect is affected by regionally unique factors that cannot be expressed by national and compositional effects.

Specifically, dynamic shift-share analysis is the equivalent of analyzing the differences in users once the national average trend has been eliminated and to dividing the components into those that can be explained as such (compositional effect) and those that cannot (regional effect).

\section{Data}

The present study undertook dynamic shift-share analysis, using total energy demand data by user, for the 47 Japanese prefectures for the period 1990-2011. Using dynamic shift-share analysis, a decomposition analysis was performed on the rate of change in the regional energy demand for the study period. The energy data came from the Energy Consumption Statistics by Prefecture (Japan's Ministry of Economy, Trade and Industry). The energy demand data used here relate to the total energy demand, including electricity and gas. However, this is the final energy consumption and does not include the primary energy consumption. The energy demand users are the industrial (manufacturing and nonmanufacturing) sectors, the civil (residential and commercial) sectors, and the transportation sectors. The production data are the real gross product, published by Japanese Annual Report on Prefectural Accounts
(Cabinet Office). The real gross product is value added and includes trades and services.

Table 1 summarizes the relevant data statistics for Japan. Comparing the average energy demand for each sector shows a constant high demand level in the manufacturing sector. The average values for the civil sectors (residential and commercial) and the transportation sector are relatively small in comparison. During the study period (1990-2011), the manufacturing sector's maximum energy demand was extremely large $(1,029,795 \mathrm{TJ}$ in 2000), and its minimum energy demand was very small (8235 TJ in 1990). In other words, there was a significant difference between the maximum and minimum values. Additionally, there was a large variation in the data for each prefecture.

In the 1990s, there was an increase in the average annual growth rate of energy demand in most sectors. Energy demand grew at $1.12 \%$ for all sectors, at $0.09 \%$ in the manufacturing sector, and at $2.98 \%$ in the commercial sector. However, in the 2000s, the overall average growth rate fell to $-0.55 \%$, driven mainly by a fall in the manufacturing sector growth rate to $-1.45 \%$. Contrastingly, energy demand in the commercial and the transportation sector increased to $1.00 \%$ and $0.81 \%$, respectively. These trends reflect the overall energy use trend at the time, namely a move from the manufacturing sector in the 1990s to the commercial sector throughout the 2000s. Looking at the absolute value of the change, the absolute amount of the energy demand reduction in the manufacturing sector is roughly equal to the increase in the energy demand in the commercial sector.

Japan's average annual value-added growth rate increased constantly in the 1990s and the 2000s. The growth rate trend represented by the value-added figures validates the energy intensity (energy demand per value added), namely a rapid drop from the 1990s to the 2000s.

\section{Results and discussion \\ Dynamic shift-share analysis}

Table 2 gives the factor decomposition results for the three effects on Japan's regional energy demand using (3). Looking at the rate of change in the energy demand, the region with the biggest rate of change was Okinawa followed by Kita-Kanto, Tohoku, Hokkaido, and then Shikoku (all provincial regions). The rates of change for the big-city regions, such as the Capital Region, Chubu, and Kansai, were relatively small. The national effect was $0.28 \%$, and thus, the remaining effects (when the national effect was removed from the rate of change for each region) were the compositional and regional effects. In Tohoku and Okinawa, both the compositional and the regional effects led the increase in energy demand. 
Table 1 Japan's energy demand by sector and real value added (1990-2011)

\begin{tabular}{|c|c|c|c|c|c|c|c|}
\hline & \multicolumn{6}{|c|}{ Energy demand (TJ) } & \multirow{3}{*}{$\begin{array}{l}\text { Regional gross product } \\
\text { (real value added: million yen) }\end{array}$} \\
\hline & \multirow{2}{*}{$\begin{array}{l}\text { All } \\
\text { sectors }\end{array}$} & \multicolumn{2}{|l|}{ Industry sector } & \multicolumn{2}{|l|}{ Civil sector } & \multirow{2}{*}{$\begin{array}{l}\text { Transportation } \\
\text { sector }\end{array}$} & \\
\hline & & $\begin{array}{l}\text { Non- } \\
\text { manufacturing }\end{array}$ & Manufacturing & Residential & Commercial & & \\
\hline \multicolumn{8}{|l|}{1990} \\
\hline Average & 244,527 & 13,270 & 142,241 & 34,041 & 39,599 & 15,376 & $9,909,019$ \\
\hline Standard deviation & 247,976 & 10,249 & 183,882 & 36,560 & 50,515 & 12,086 & $13,927,556$ \\
\hline Maximum & $1,111,732$ & 60,233 & 909,773 & 180,245 & 296,525 & 46,492 & $86,871,666$ \\
\hline Minimum & 34,509 & 3,547 & 8,235 & 6,416 & 8,053 & 3,562 & $1,925,717$ \\
\hline \multicolumn{8}{|l|}{2000} \\
\hline Average & 273,370 & 11,446 & 143,552 & 44,268 & 53,108 & 20,996 & $10,658,548$ \\
\hline Standard deviation & 273,460 & 7,930 & 193,543 & 46,249 & 63,634 & 16,041 & $14,683,460$ \\
\hline Maximum & $1,293,160$ & 48,073 & $1,029,795$ & 222,472 & 377,043 & 62,358 & $93,069,156$ \\
\hline Minimum & 48,724 & 3,400 & 9,434 & 8,776 & 11,810 & 5,262 & $2,108,983$ \\
\hline $\begin{array}{l}\text { Annual growth rate } \\
(\%, 1990-2000)\end{array}$ & 1.12 & -1.47 & 0.09 & 2.66 & 2.98 & 3.16 & 0.73 \\
\hline \multicolumn{8}{|l|}{2011} \\
\hline Average & 258,754 & 10,149 & 124,003 & 43,201 & 58,636 & 22,765 & $11,372,417$ \\
\hline Standard deviation & 252,082 & 8,098 & 167,884 & 45,175 & 72,779 & 16,667 & $15,518,250$ \\
\hline Maximum & $1,096,462$ & 44,894 & 829,755 & 221,439 & 427,226 & 66,374 & $97,824,880$ \\
\hline Minimum & 48,044 & 1,833 & 10,313 & 8,300 & 12,291 & 6,253 & $1,876,725$ \\
\hline $\begin{array}{l}\text { Annual growth rate } \\
(\%, 2000-2011)\end{array}$ & -0.55 & -1.20 & -1.45 & -0.24 & 1.00 & 0.81 & 0.65 \\
\hline \multicolumn{8}{|l|}{ 1990-2011 } \\
\hline Average & 262,696 & 11,824 & 135,589 & 41,833 & 52,096 & 21,354 & $10,633,278$ \\
\hline Standard deviation & 259,215 & 8,684 & 180,259 & 43,555 & 65,180 & 16,501 & $14,495,885$ \\
\hline Maximum & $1,333,681$ & 60,689 & $1,062,885$ & 232,676 & 476,685 & 84,744 & $101,626,400$ \\
\hline Minimum & 34,509 & 1,719 & 7,630 & 6,416 & 8,044 & 3,562 & $1,869,686$ \\
\hline $\begin{array}{l}\text { Annual growth rate } \\
(\%, 1990-2011)\end{array}$ & 0.33 & -0.52 & -0.22 & 0.94 & 1.25 & 1.50 & 0.32 \\
\hline
\end{tabular}

Source: Energy Consumption Statistics by Prefecture (METI), Japanese Annual Report on Prefectural Accounts (Cabinet Office)

Notes: Japan's 47 prefectures are included in the sample dataset for 1990-2011

However, in Hokkaido and Hokuriku, while the compositional effect contributed to an increase in energy demand, the regional effect's contribution was negative. Conversely, in Japan's western regions, such as Chugoku, Shikoku, and Kyushu, the regional effect's contribution to the increase in energy demand was larger than that of the compositional effect. The lowering of the energy demand in the big-city regions (excluding the Capital Region), such as Chubu and Kansai, was affected appreciably by the regional effects. Particularly, the contributions of the effects were negative for Chubu and Kansai. This reveals that in the big-city regions, the energy demand fell via differences arising from regionalspecific factors.

Table 3 gives the energy demand decomposition results for Japan's prefectures using dynamic shift-share analysis. The energy demand increase exceeded $1 \%$ in Miyagi, Nara, Tottori, Saga, Kumamoto, Kagoshima, and Okinawa prefectures. Conversely, the rate of change was negative in several prefectures, including Toyama, Shizuoka, Mie, Osaka, Wakayama, Okayama, Hiroshima, and Fukuoka prefectures. A positive sign represents a positive effect on the rate of change in energy demand. A negative sign represents a negative effect on the rate of change in energy demand. The national effect is positive but is not dominant. It is important to understand the characteristics of each prefecture, in relation to the regional differences arising from the compositional and the regional effects of energy demand. Hence, the prefectures were classified according to four quadrants, formed by the compositional effect on the horizontal axis and the regional effect on the vertical axis (Fig. 1). 
Table 2 Factor decomposition of energy demand by Japanese region (1990-2011)

\begin{tabular}{lllll}
\hline & $\begin{array}{l}\text { Rate of change } \\
\text { in energy } \\
\text { demand (\%) } \\
\text { (i) }+ \text { (ii) }+ \text { (iii) }\end{array}$ & $\begin{array}{l}\text { National } \\
\text { effect }\end{array}$ & $\begin{array}{l}\text { Compositional } \\
\text { effect }\end{array}$ & $\begin{array}{l}\text { Regional } \\
\text { effect }\end{array}$ \\
\hline Hokkaido & 0.50 & 0.28 & 0.29 & (ii) \\
Tohoku & 0.65 & 0.28 & 0.27 & -0.07 \\
Kita-Kanto & 0.74 & 0.28 & -0.07 & 0.09 \\
Capital & 0.36 & 0.28 & 0.08 & 0.00 \\
Region & & 0.28 & -0.03 & -0.22 \\
Chubu & 0.03 & 0.28 & -0.23 \\
Hokuriku & 0.29 & 0.28 & 0.24 & -0.36 \\
Kansai & 0.01 & 0.28 & 0.09 & 0.33 \\
Chugoku & 0.19 & 0.28 & -0.42 & 0.22 \\
Shikoku & 0.41 & 0.28 & -0.09 & 0.07 \\
Kyushu & 0.27 & 0.28 & -0.08 & 0.34 \\
Okinawa & 1.22 & 0.28 & 0.60 & \\
\hline
\end{tabular}

Notes:

1. The rate of change is the annual average (\%) for 1990-2011

2. The regions are broken down as follows:

Hokkaido (Hokkaido)

Tohoku (Aomori, Iwate, Miyagi, Akita, Yamagata, Fukushima, Niigata)

Kita-Kanto (Ibaraki, Tochigi, Gunma, Yamanashi)

Capital Region (Saitama, Chiba, Tokyo, Kanagawa)

Chubu (Nagano, Gifu, Shizuoka, Aichi, Mie)

Hokuriku (Toyama, Ishikawa, Fukui)

Kansai (Shiga, Kyoto, Osaka, Hyogo, Nara, Wakayama)

Chugoku (Tottori, Shimane, Okayama, Hiroshima, Yamaguchi)

Shikoku (Tokushima, Kagawa, Ehime, Kochi)

Kyushu (Fukuoka, Saga, Nagasaki, Kumamoto, Oita, Miyazaki, Kagoshima)

Okinawa (Okinawa)

The compositional and the regional effects are both positive in the first quadrant: a characteristic of many of the prefectures that are not in big-city regions. In the second quadrant, the compositional effect is negative, and the regional effect is positive. Many of the provincial prefectures that have an agglomeration of heavy and chemical industries, which includes the petrochemical industrial complex, are in this quadrant. In the third quadrant, both the compositional and the regional effects are negative. The prefectures of regions that have an agglomeration of processing and assembly industries are in this quadrant. In the fourth quadrant, the compositional effect is positive and the regional effect is negative. Many prefectures that belong to the big-city regions with commercial sector agglomeration are in this quadrant. This quadrant also includes some provincial prefectures, such as Hokkaido, Toyama, Ishikawa, and Kochi.

These observations show that the positive/negative state of the compositional effect appears to be subject to the agglomeration degree of the manufacturing industries. Further, the positive/negative state of the regional effect seems to be subject to whether the region is a bigcity region or a provincial region.

\section{Analysis of the compositional effect}

The dynamic shift-share analysis shows a high correlation between the level of agglomeration of the manufacturing sector and the positive or negative state of the compositional effect. Therefore, it is worth investigating this relationship in more detail. The differences in the compositional effect among the prefectures depend on the users (industrial, civil, or transportation sectors) in each prefecture. Here, the article verifies which user has an effect on the compositional effect according to a location quotient showed by McCann [23]. A location quotient is usually calculated using the number of employees. The article calculates this location quotient for energy demand. The location quotient (represented by $L Q$ ) of the energy demand of user $i$ in region $j$ in time $t$ is given by

$$
L Q_{i j, t}=\frac{E_{i j, t} / E_{j, t}}{E_{i, t} / E_{t}}
$$

The numerator shows the energy demand share of user $i$ in region $j$. The denominator shows the energy demand share of user $i$ for the entire nation. Accordingly, if the index exceeds one, then the region's energy demand share of user $i$ is higher than that of the entire nation. If the index exceeds one, then the region has a comparative agglomeration of that user.

Table 4 gives the correlation coefficient between the compositional effect and the location quotient, calculated for $1990(t=1990)$. The results show a negative trend for the compositional effect when a region specializes in manufacturing, particularly for the chemical, chemical textile, and pulp and paper sectors, and the iron and steel, non-ferrous metal, and cement and ceramics sectors. Meanwhile, the results also show a positive trend for the compositional effect for regions that specialize in civil activities, such as the residential and commercial sectors and the transportation sector centered on passenger vehicles.

The following observations are made from checking the location quotient of the energy demand by user for the five highest-ranking prefectures, and the five lowestranking prefectures, with respect to the rate of change by compositional effect. For the highest-ranking prefectures, the location quotient for the residential, commercial, and transportation sectors was more than one, and high. In contrast, the location quotient of the heavy and chemical industries (particularly the chemical, chemical textile, and pulp and paper industry, and the iron and steel, non-ferrous metal, and cement and ceramics industry) is close to zero, and extremely low. For the lowest ranking prefectures, this relationship is reversed.

In other words, in prefectures that specialize in civil activities (including the residential and commercial 
Table 3 Factor decomposition of Japan's prefectural energy demand (1990-2011)

\begin{tabular}{|c|c|c|c|c|}
\hline & $\begin{array}{l}\text { Rate of change } \\
\text { in energy } \\
\text { demand (\%) }\end{array}$ & $\begin{array}{l}\text { National } \\
\text { effect }\end{array}$ & $\begin{array}{l}\text { Compositional } \\
\text { effect }\end{array}$ & $\begin{array}{l}\text { Regional } \\
\text { effect }\end{array}$ \\
\hline & (i) + (ii) + (iii) & (i) & (ii) & (iii) \\
\hline Hokkaido & 0.50 & 0.28 & 0.29 & -0.07 \\
\hline Aomori & 0.62 & 0.28 & 0.13 & 0.21 \\
\hline Iwate & 0.47 & 0.28 & 0.24 & -0.05 \\
\hline Miyagi & 1.06 & 0.28 & 0.38 & 0.40 \\
\hline Akita & 0.97 & 0.28 & 0.39 & 0.29 \\
\hline Yamagata & 0.63 & 0.28 & 0.50 & -0.15 \\
\hline Fukushima & 0.58 & 0.28 & 0.28 & 0.02 \\
\hline Ibaraki & 0.82 & 0.28 & -0.28 & 0.83 \\
\hline Tochigi & 0.82 & 0.28 & 0.16 & 0.38 \\
\hline Gunma & 0.47 & 0.28 & 0.20 & -0.02 \\
\hline Saitama & 0.80 & 0.28 & 0.46 & 0.05 \\
\hline Chiba & 0.05 & 0.28 & -0.45 & 0.22 \\
\hline Tokyo & 0.55 & 0.28 & 0.89 & -0.62 \\
\hline Kanagawa & 0.55 & 0.28 & -0.07 & 0.33 \\
\hline Niigata & 0.42 & 0.28 & 0.16 & -0.02 \\
\hline Toyama & -0.18 & 0.28 & 0.00 & -0.46 \\
\hline Ishikawa & 0.71 & 0.28 & 0.53 & -0.10 \\
\hline Fukui & 0.63 & 0.28 & 0.34 & 0.01 \\
\hline Yamanashi & 0.92 & 0.28 & 0.49 & 0.15 \\
\hline Nagano & 0.50 & 0.28 & 0.40 & -0.18 \\
\hline Gifu & 0.57 & 0.28 & 0.25 & 0.04 \\
\hline Shizuoka & -0.20 & 0.28 & 0.03 & -0.52 \\
\hline Aichi & 0.16 & 0.28 & -0.01 & -0.12 \\
\hline Mie & -0.35 & 0.28 & -0.42 & -0.21 \\
\hline Shiga & 0.34 & 0.28 & -0.04 & 0.09 \\
\hline Kyoto & 0.66 & 0.28 & 0.56 & -0.18 \\
\hline Osaka & -0.25 & 0.28 & 0.29 & -0.83 \\
\hline Hyogo & 0.13 & 0.28 & -0.19 & 0.03 \\
\hline Nara & 1.06 & 0.28 & 0.60 & 0.18 \\
\hline Wakayama & -0.30 & 0.28 & -0.37 & -0.21 \\
\hline Tottori & 1.57 & 0.28 & 0.24 & 1.05 \\
\hline Shimane & 0.57 & 0.28 & 0.29 & 0.00 \\
\hline Okayama & -0.06 & 0.28 & -0.60 & 0.25 \\
\hline Hiroshima & -0.04 & 0.28 & -0.24 & -0.09 \\
\hline Yamaguchi & 0.87 & 0.28 & -0.53 & 1.12 \\
\hline Tokushima & 0.23 & 0.28 & 0.06 & -0.11 \\
\hline Kagawa & 0.15 & 0.28 & -0.05 & -0.08 \\
\hline Ehime & 0.69 & 0.28 & -0.22 & 0.63 \\
\hline Kochi & 0.36 & 0.28 & 0.10 & -0.02 \\
\hline Fukuoka & -0.11 & 0.28 & 0.04 & -0.43 \\
\hline Saga & 1.43 & 0.28 & 0.38 & 0.77 \\
\hline
\end{tabular}

Table 3 Factor decomposition of Japan's prefectural energy demand (1990-2011) (Continued)

\begin{tabular}{lllll}
\hline Nagasaki & 0.44 & 0.28 & 0.42 & -0.26 \\
Kumamoto & 1.25 & 0.28 & 0.34 & 0.63 \\
Oita & 0.24 & 0.28 & -0.61 & 0.57 \\
Miyazaki & 0.18 & 0.28 & 0.04 & -0.14 \\
Kagoshima & 1.12 & 0.28 & 0.36 & 0.48 \\
Okinawa & 1.22 & 0.28 & 0.60 & 0.34
\end{tabular}

Note: The rate of change is the annual average (\%) for 1990-2011

sectors and the transportation sector), the rate of increase in energy demand is large. Meanwhile, in prefectures that specialize in heavy and chemical industries, a negative rate of change is observed for energy demand by way of the compositional effect.

\section{Analysis of the regional effect}

The differences in the compositional effect rely on differences in the specialization of the energy user of each prefecture. The differences in the regional effect rely on the differences in the regionally unique characteristics of each of the prefecture's energy users. The results of dynamic shift-share analysis show a high correlation between the positive or negative state of the regional (bigcity versus provincial regions) effect, and it is worth investigating this relationship in greater detail. To gain a more detailed understanding, the portion of the regional effect $\sum_{i} s_{i j}\left[g\left(E_{i j}\right)-g\left(E_{i}\right)\right]$ in (3) is resolved into the degree of energy intensity and the real gross product (value added). ${ }^{3}$

First, the region's energy consumption for each user can be resolved with approximate equations using the formula

$$
g\left(E_{i j}\right)=g\left(E_{i j} / Y_{j}\right)+g\left(Y_{j}\right),
$$

where $Y_{j}$ is the real gross product of region $j$, and $E_{i j} /$ $Y_{j}$ is the energy intensity of user $i$ in region $j$. Moreover, the nation's energy consumption for each user can be resolved with approximate equations using the formula

$$
g\left(E_{i}\right)=g\left(E_{i} / Y\right)+g(Y),
$$

where $Y$ is the national gross product, and $E_{i} / Y$ is the national energy intensity for user $i$. Substituting (4) and (5) into the regional effect portion of (3) yields

$$
\begin{aligned}
\sum_{i} s_{i j}\left[g\left(E_{i j}\right)-g\left(E_{i}\right)\right]= & \sum_{i} s_{i j}\left[g\left(E_{i j} / Y_{j}\right)-g\left(E_{i} / Y\right)\right] \\
& +\left[g\left(Y_{j}\right)-g(Y)\right] .
\end{aligned}
$$

The regional effect is expressed as the sum of the change of energy intensity and regional gross product, specifically, as follows. 


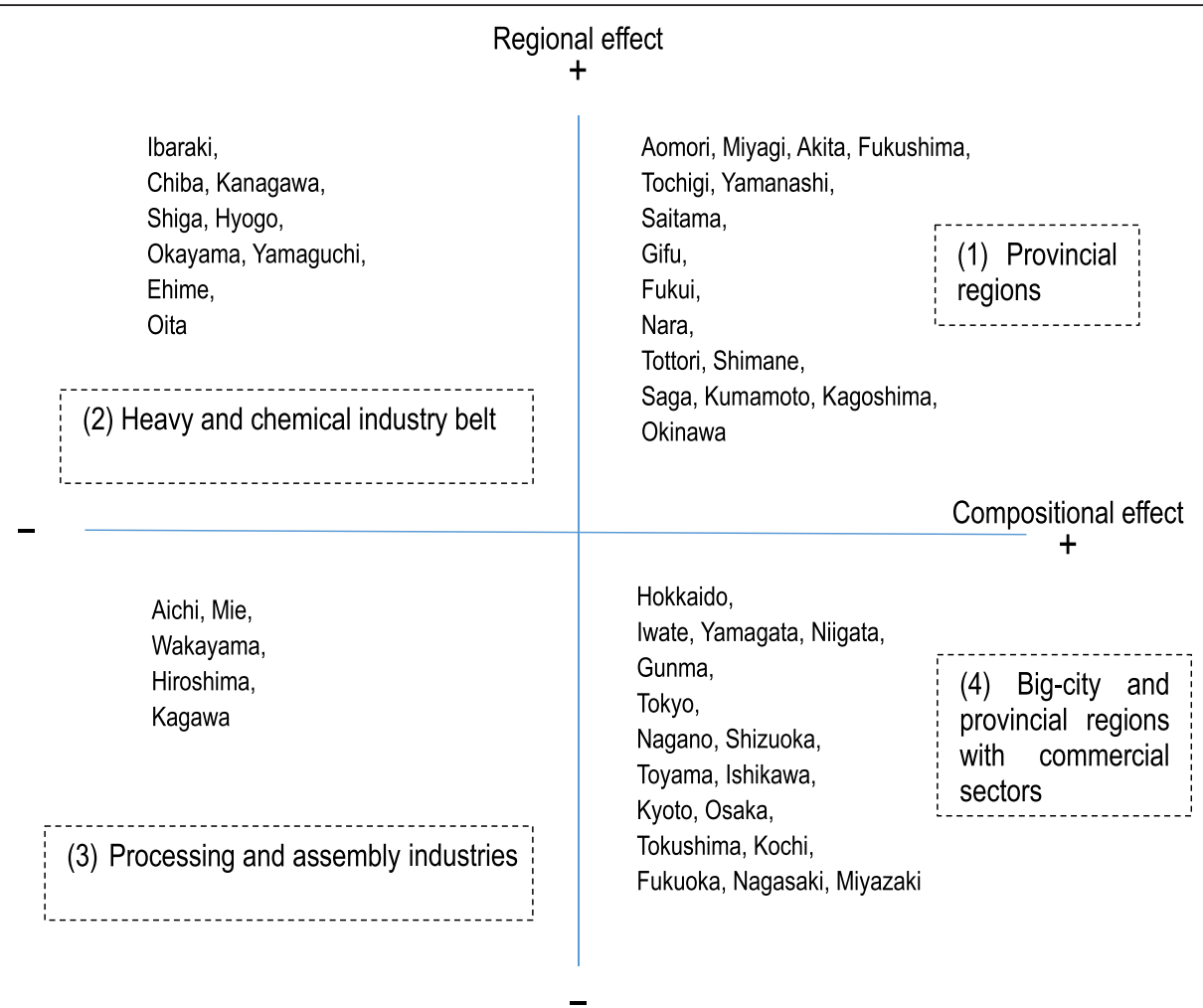

Fig. 1 Quadrant classification of Japan's prefectures by compositional effect and regional effects (1990-2011)

Energy-intensity effect: $\sum_{i} s_{i j}\left[g\left(E_{i j} / Y_{j}\right)-g\left(E_{i} / Y\right)\right]$

Production effect: $\left[g\left(Y_{j}\right)-g(Y)\right]$

Table 5 gives the results of the decomposition using (6). The regional effect is not attributable to an energy user composition; therefore, it is difficult to discuss the regional effect contributions that give rise to energy intensity and production activity as a trend of the compositional difference by user. Therefore, this paper considers the breakdown of the factor analysis results for both the top-ranking and the bottom-ranking prefectures, in terms of the rate of change attributable to the regional effect.

The top-ranking prefectures in terms of the rate of change attributable to the regional effect are in provincial regions, i.e., Yamaguchi prefecture, followed by Tottori, Ibaraki, Saga, and Ehime prefectures. An observable characteristic of these regions is that, except for Tottori prefecture, both the energy-intensity and the production effects contribute positively. For the ten top-ranking prefectures, both of these factors contribute positively to the regional effect, and no notable differences in the size of this contribution are observed. Meanwhile, the bottom-ranking prefectures are those in the big-city regions, with Osaka at the very bottom, followed by Tokyo, Shizuoka, Toyama, and Fukuoka prefectures. An observable characteristic of these regions is that the energy-intensity effects are all negative. Moreover, there is a tendency for the size of these effects to exceed the production effect. Therefore, it is highly possible that the rate of change in the regional effect is negative mainly owing to a declining energy-intensity effect. Note that the energy-intensity effect for the ten bottomranking prefectures is negative.

Accordingly, the obtained results suggest that it is possible to explain the differences between big-city and provincial regions, which are expressed as the regional differences of the regional effect, i.e., differences not in the production effect but in the energy-intensity effect. Last, the correlation coefficient between the regional effect and the energy-intensity effect is 0.76 and that between the regional effect and the production effect is 0.08 . This shows that the correlation coefficient between the regional effect and the energy-intensity effect is relatively high, compared with that between the regional effect and production effect.

\section{Conclusions}

To clarify what factors determine the fluctuations in the regional energy demand in Japan, this study applied dynamic shift-share analysis to the fluctuations in regional energy demand. The results show that although there is a positive contribution from the national effect, it is not dominant. Further, the positive and the negative 
Table 4 Factor decomposition of the compositional effect in Japan, by sector and prefecture

\begin{tabular}{|c|c|c|c|c|c|c|c|c|c|c|c|c|}
\hline & \multicolumn{4}{|c|}{ Industrial sector } & & \multicolumn{6}{|l|}{ Civil sector } & \multirow{3}{*}{$\begin{array}{l}\text { Transportation } \\
\text { sector } \\
\text { Cars }\end{array}$} \\
\hline & \multicolumn{2}{|c|}{$\begin{array}{l}\text { Non- } \\
\text { manufacturing }\end{array}$} & \multicolumn{2}{|l|}{ Manufacturing } & \multirow[b]{2}{*}{ Machinery } & \multirow[t]{2}{*}{ Residential } & \multicolumn{5}{|c|}{ Commercial and others } & \\
\hline & $\begin{array}{l}\text { Agriculture, } \\
\text { forestry, } \\
\text { and fishery }\end{array}$ & $\begin{array}{l}\text { Construction } \\
\text { and } \\
\text { mining }\end{array}$ & $\begin{array}{l}\text { Chemical, } \\
\text { chemical textile, } \\
\text { pulp and paper }\end{array}$ & $\begin{array}{l}\text { Iron and } \\
\text { steel, } \\
\text { non-ferrous } \\
\text { metals, } \\
\text { cement and } \\
\text { ceramics }\end{array}$ & & & $\begin{array}{l}\text { Water } \\
\text { supply, } \\
\text { sewage } \\
\text { and } \\
\text { waste } \\
\text { disposal }\end{array}$ & $\begin{array}{l}\text { Trade } \\
\text { and } \\
\text { finance } \\
\text { services }\end{array}$ & $\begin{array}{l}\text { Public } \\
\text { services }\end{array}$ & $\begin{array}{l}\text { Commercial } \\
\text { services }\end{array}$ & $\begin{array}{l}\text { Retail } \\
\text { services }\end{array}$ & \\
\hline $\begin{array}{l}\text { Correlation } \\
\text { coefficient } \\
\text { between the } \\
\text { composition } \\
\text { effect and } \\
\text { location quotient }\end{array}$ & 0.21 & 0.89 & -0.74 & -0.69 & 0.16 & 0.95 & 0.79 & 0.86 & 0.87 & 0.93 & 0.94 & 0.81 \\
\hline \multicolumn{13}{|c|}{ Five top-ranking prefectures in compositional effect: location quotient } \\
\hline Tokyo & 0.06 & 2.35 & 0.04 & 0.10 & 0.59 & 1.90 & 2.69 & 3.18 & 2.47 & 2.69 & 2.62 & 1.07 \\
\hline Okinawa & 1.66 & 1.66 & 0.01 & 0.25 & 0.00 & 1.69 & 1.66 & 1.66 & 1.68 & 1.66 & 1.66 & 2.47 \\
\hline Nara & 0.65 & 1.93 & 0.02 & 0.01 & 0.96 & 2.06 & 1.87 & 1.35 & 1.93 & 1.49 & 1.55 & 2.07 \\
\hline Kyoto & 0.30 & 1.25 & 0.16 & 0.28 & 1.86 & 1.82 & 2.06 & 2.05 & 1.88 & 1.76 & 1.80 & 1.25 \\
\hline Ishikawa & 2.14 & 1.55 & 0.09 & 0.07 & 1.27 & 1.74 & 0.87 & 1.68 & 1.48 & 1.70 & 1.72 & 2.23 \\
\hline \multicolumn{13}{|c|}{ Five bottom-ranking prefectures in compositional effect: location quotient } \\
\hline Mie & 1.11 & 0.52 & 2.84 & 0.19 & 0.98 & 0.44 & 0.38 & 0.30 & 0.41 & 0.41 & 0.42 & 0.68 \\
\hline Chiba & 0.24 & 0.50 & 2.29 & 1.25 & 0.18 & 0.47 & 0.66 & 0.31 & 0.45 & 0.36 & 0.36 & 0.47 \\
\hline Yamaguchi & 0.63 & 0.38 & 2.35 & 1.16 & 0.30 & 0.39 & 0.34 & 0.29 & 0.32 & 0.38 & 0.39 & 0.51 \\
\hline Okayama & 0.18 & 0.28 & 2.15 & 1.61 & 0.43 & 0.27 & 0.21 & 0.23 & 0.20 & 0.27 & 0.27 & 0.33 \\
\hline Oita & 0.82 & 0.30 & 1.77 & 2.08 & 0.17 & 0.24 & 0.06 & 0.19 & 0.27 & 0.25 & 0.26 & 0.39 \\
\hline
\end{tabular}

Notes: Location quotient is the value of $1990(t=1990)$ 
Table 5 Factor decomposition of the regional effect in Japan

\begin{tabular}{|c|c|c|c|}
\hline & Regional effect & Energy-intensity effect & Production effect \\
\hline Hokkaido & -0.07 & 0.18 & -0.27 \\
\hline Aomori & 0.21 & 0.10 & 0.15 \\
\hline Iwate & -0.05 & 0.08 & -0.12 \\
\hline Miyagi & 0.40 & 0.66 & -0.27 \\
\hline Akita & 0.29 & 0.66 & -0.35 \\
\hline Yamagata & -0.15 & 0.14 & -0.26 \\
\hline Fukushima & 0.02 & 0.40 & -0.35 \\
\hline Ibaraki & 0.83 & 0.43 & 0.48 \\
\hline Tochigi & 0.38 & 0.27 & 0.14 \\
\hline Gunma & -0.02 & -0.24 & 0.25 \\
\hline Saitama & 0.05 & -0.18 & 0.23 \\
\hline Chiba & 0.22 & 0.07 & 0.17 \\
\hline Tokyo & -0.62 & -0.53 & -0.09 \\
\hline Kanagawa & 0.33 & 0.43 & -0.06 \\
\hline Niigata & -0.02 & -0.12 & 0.10 \\
\hline Toyama & -0.46 & -0.33 & -0.10 \\
\hline Ishikawa & -0.10 & 0.27 & -0.37 \\
\hline Fukui & 0.01 & -0.24 & 0.26 \\
\hline Yamanashi & 0.15 & 0.12 & 0.07 \\
\hline Nagano & -0.18 & -0.33 & 0.17 \\
\hline Gifu & 0.04 & 0.08 & -0.03 \\
\hline Shizuoka & -0.52 & -0.82 & 0.37 \\
\hline Aichi & -0.12 & -0.34 & 0.31 \\
\hline Mie & -0.21 & -0.76 & 0.60 \\
\hline Shiga & 0.09 & -0.59 & 0.70 \\
\hline Kyoto & -0.18 & -0.27 & 0.11 \\
\hline Osaka & -0.83 & -0.13 & -0.68 \\
\hline Hyogo & 0.03 & 0.41 & -0.36 \\
\hline Nara & 0.18 & 0.41 & -0.24 \\
\hline Wakayama & -0.21 & -0.59 & 0.42 \\
\hline Tottori & 1.05 & 1.80 & -0.74 \\
\hline Shimane & 0.00 & -0.08 & 0.06 \\
\hline Okayama & 0.25 & 0.03 & 0.28 \\
\hline Hiroshima & -0.09 & -0.01 & -0.02 \\
\hline Yamaguchi & 1.12 & 0.90 & 0.25 \\
\hline Tokushima & -0.11 & -0.75 & 0.64 \\
\hline Kagawa & -0.08 & -0.25 & 0.19 \\
\hline Ehime & 0.63 & 0.26 & 0.40 \\
\hline Kochi & -0.02 & 0.46 & -0.50 \\
\hline Fukuoka & -0.43 & -0.79 & 0.35 \\
\hline Saga & 0.77 & 0.55 & 0.23 \\
\hline Nagasaki & -0.26 & -0.46 & 0.19 \\
\hline Kumamoto & 0.63 & 0.62 & 0.04 \\
\hline Oita & 0.57 & 0.30 & 0.33 \\
\hline
\end{tabular}

Table 5 Factor decomposition of the regional effect in Japan (Continued)

\begin{tabular}{lrrl}
\hline Miyazaki & -0.14 & -0.43 & 0.27 \\
Kagoshima & 0.48 & 0.16 & 0.29 \\
Okinawa & 0.34 & -0.27 & 0.60 \\
\hline
\end{tabular}

fluctuations in regional energy demands are determined by both the compositional and the regional effects.

The study found that the compositional effect contributes most to energy demand growth in the prefectures that specialize in the civil and transportation sectors. Further, the compositional effect does not contribute to energy demand growth in the prefectures that specialize in the heavy and chemical industries of the manufacturing sector. Moreover, the study found that among the regional effects, the improvement in energy intensity through energy conservation (which is promoted mainly in big-city regions) contributes to constraining the energy demand. For example, because of improved energy intensity, the energy demand declined in Mie, Wakayama, Osaka, Shizuoka, Toyama, Fukuoka, and Hiroshima prefectures. That is, the regional effects in big-city regions are comparable and differ significantly from rural regions in terms of energy demand. This paper attributes this observation to the promotion of energy conservation in big-city regions. Future research could investigate the differences between rural and urban areas in Japan that might prove to be causal to the statistical data used in this analysis.

The study concludes that the findings are reasonable, as the dynamic shift-share analysis focuses on the rate of change. The study expected that the compositional effect-expressing the degree by which the national energy demand from each energy user exceeds the rate of change of the national energy demand-would be low in the manufacturing industry, because energy demand changes mainly arise from efficiency efforts in this sector. The study also verifies that the agglomeration of industry enforces this effect (Otsuka et al. [5], Otsuka and Goto [6]). The study results are fully consistent with these insights.

The finding that the compositional and the regional effects are relevant to energy demand changes shows that having a mixture of industry and civil sector businesses in a region, potentially flattens out the fluctuations in energy demand changes. This suggests that when moderating the change of regional energy demand, it is important to diversify the industrial structure in each region. This finding should make an important contribution to planning 
Japan's national energy master plan. This result suggests that it is necessary to take into account the differences between the energy users and the regions to investigate the future trends of energy demand in Japan accurately.

Compared with static shift-share analysis, dynamic shift-share analysis accounts for the time variation of the industrial structure. In other words, dynamic shift-share analysis does not assume a time-fixed structure in energy demand, to enable the factor decomposition of continuous change in energy demand. That is, using dynamic shift-share analysis can alleviate a static shift-share analysis problem: the potential over- or under-estimation of the energy change rate. Therefore, when evaluating the fluctuations in energy demand, the Japanese Government should adopt a dynamic approach to capture the fluctuation of energy demand in a continuous time change, rather than fixing the observation period in a two-point static approach. However, to assess the dynamic structure on the energy demand in detail, it is necessary to further decompose the regional differences in the energy demand by the energy user. This is a topic for future research on energy demand forecasting.

\section{Endnotes}

${ }^{1}$ The energy demand drivers are also related to other issues, such as sociology (household size development, income-related luxury demands), technological advancement, or climate policies. However, to precisely investigate the impact of such issues on changes in energy demand requires an econometric analysis rather than a shift-share analysis. This is because shift-share analysis is only one of the decomposition methods (Metcalf [3]).

${ }^{2}$ The dynamic approach is a suitable way to address the question of the representational adequacy of a continuous time in discrete models (Mitchell [20]).

${ }^{3}$ There is a method of dividing to identify the finer factors. However, the calculation becomes inflation. This paper is simplified to the two factors that seem dominant.

\section{Competing interests}

The author declares that he has no competing interests.

\section{Author's contributions}

The author conducted the analysis and drafted the manuscript.

Author's information

Dr. Otsuka is an associate professor at the Yokohama City University, Japan.

\section{Acknowledgements}

The author is grateful to anonymous reviewers for their helpful comments and suggestions.

\section{Funding}

This work was supported by a Japan Society for the Promotion of Science (JSPS) Grant-in-Aid for Scientific Research (KAKENHI) 15K17067.
Received: 21 September 2015 Accepted: 27 March 2016

Published online: 19 April 2016

\section{References}

1. Ministry of Economy, Trade and Industry (METI), Agency for Natural Resources and Energy (2015) Outline of the FY2014 Annual Report on Energy (Energy White Paper 2015). http://www.meti.go.jp/english/report/ downloadfiles/2015_outline.pdf. Accessed 16 Mar 2016.

2. Bernstein MA, Fonkych K, Loeb S, Loughran DS (2003) State-level changes in energy intensity and their national implications., Rand Corp

3. Metcalf GE (2008) An empirical analysis of energy intensity and its determinants at the state level. Energ J 29(3):1-26

4. Raupach-Sumiya J, Matsubara H, Prahl A, Aretz A, Salecki S (2015) Regional economic effects of renewable energies-comparing Germany and Japan. Energ Sustain Soc 5(1):1-17. doi:10.1186/s13705-015-0036-x

5. Otsuka A, Goto M, Sueyoshi T (2014) Energy efficiency and agglomeration economies: the case of Japanese manufacturing industries. Reg Sci Pol Pract 6(2):195-212

6. Otsuka A, Goto M (2015) Estimation and determinants of energy efficiency in Japanese regional economies. Reg Sci Pol Pract 7(2):89-101

7. Dunn ES (1960) A statistical and analytical technique for regional analysis. Pap Reg Sci 6(1):97-112

8. Dinc M, Haynes KE (1999) Source of regional inefficiency: an integrated shift-share, data envelopment analysis and input-output approach. Ann Regional Sci 33(4):469-489

9. Haynes KE, Dinc M (1997) Productivity change in manufacturing regions: a multifactor/shift-share approach. Growth Change 28(2):201-221

10. Dawson JA (1982) Shift-share analysis: a bibliographic review of technique and applications. (No. 949). Vance Bibliographies, Monticello

11. Knudsen DC, Barff RA (1991) Shift-share analysis as a linear model. Environ Plann A 23(3):421-431

12. Artige L, Neuss LV (2014) A new shift-share method. Growth Change 45(4):667-683

13. Barff RA, Knight PL III (1988) Dynamic shift-share analysis. Growth Change 19(2):1-10

14. Esteban-Marquillas JM (1972) A reinterpretation of shift-share analysis. Reg Urban Econ 2(3):249-255

15. Haynes KE, Machunda ZB (1987) Considerations in extending shift-share analysis: note. Growth Change 18(2):69-78

16. Markusen AR, Nooponen H, Driessen K (1991) International trade, productivity, and US regional job growth: a shift-share interpretation. Int Reg Sci Rev 14(1):15-39

17. Marquez MA, Ramajo J, Hewings GJD (2009) Incorporating sectoral structure into shift-share analysis. Growth Change 40(4):594-618

18. Hirobe T (2015) Economic shift-share effects and spatial agglomeration regarding inter-regional disparities of labour market in the USA. Reg Sci Pol Prac 7(3):103-117

19. Kobayashi N (2004) Industrial structure and manufacturing growth during Japan's bubble and post-bubble economics. Reg Stud 38(4):429-444

20. Mitchell W, Carlson E (2005) Exploring employment growth disparities across metropolitan and regional Australia. Austral J Reg Stud 11(1):25-40

21. Nissan E, Carter G (1994) An extension to the shift-share technique for predicting and evaluating changes in employment growth. J Reg Anal Pol 24(2):49-67

22. Shi C, Zhang J, Yang Y, Zhang Z (2007) Shift-share analysis on international tourism competitiveness: a case of Jiangsu province. Chinese Geogr Sci 17(2):173-178

23. McCann P (2001) Urban and regional economics. Oxford University Press, New York 